\title{
Interactive comment on "Vegetation dynamics and responses to climate anomalies in East Africa" by John Musau et al.
}

\section{Anonymous Referee \#2}

Received and published: 21 February 2018

Although not ground breaking, this paper presents a solid co-analysis of available long time series of LAI and SPEI with reference to the Global Human Footprint index in East-Africa.

What is disturbing though is that the abstract states: "Much-needed reference point for the disentanglement of historical climatic- and human-induced vegetation dynamics" while a p.14, L3 it is stated: "However, further analysis is required to disentangle human and climatic induced causes of these variations"

More thorough discussion of the disentanglement of vegetation dynamics into a 
2018.

ESDD

Interactive comment

Printer-friendly version

Discussion paper 